\title{
Fashion, Sociology of
}

Sellerberg Ann-Mari, Lund University, Lund, Sweden

Aspers Patrik, Uppsala University, Uppsala, Sweden

(C) 2015 Elsevier Ltd. All rights reserved.

This article is a revision of the previous edition article by M. Sellerberg, Volume 8, pp. 5411-5415, (c) 2001, Elsevier Ltd.

\begin{abstract}
Fashion is a social phenomenon par excellence. A simple sociological definition of fashion is 'being first with the latest.' Its underlying principle is revealed in the link between the modus derivatives and the term 'modern,' with its original meaning of 'now' or 'for today.' Fashion revolves around imitation and diffusion, and it applies to all domains of social life, though most of the research is on garments. The field of fashion has been neglected, but since the mid-1990s, it has attracted sociologists studying production of fashion, identity, and the body in relation to fashion. What is lacking is theory development.
\end{abstract}

\section{Introduction}

Fashion is a social phenomenon par excellence. As a phenomenon it may be as old as mankind, but became common with the emergence of consumer society in the nineteenth century. It was then that social scientists started to show interest in fashion. A simple sociological definition of fashion is 'being first with the latest.' The definition implies that fashion is about change, and that an object, style, or activity stands out against a backdrop of stability. A fashion is understood as being right in a specific time and context. What is right is 'defined' by a clique of people, fashion leaders, who others see as having the status to determine what is in fashion. Fashion needs followers, but it is also necessary that some people are out of fashion, since not everyone, or everything, can be 'in fashion.' In fact, once something is too common it is likely to be replaced; if not, fashion cannot be used to make distinctions. Thus, fashion is a recurrent phenomenon that creates its own history, from which ideas may be reused or reinterpreted.

While the word 'fashion' in English comes originally from the Latin facere, to make, in many European languages it derives from modus, to measure. From the sixteenth century, fashion refers to conformation to existing taste, which is also when the notion got a more contemporary meaning. Mode refers to manner, and there is a strong connection to 'modern' and 'modernity,' concepts that are connected to capitalism and development. Its underlying principle is revealed in the link between the modus derivatives and the term 'modern,' with its original meaning of 'now' or 'for todays.' Fashion is a general social phenomenon of diffusion, but which in both everyday life and in the social sciences mainly means garments, and in particular haute couture. However, already Blumer outlined a much larger scope of fashion: "painting, music, drama, architecture, household decoration, entertainment, literature ... medical practice, business management, political doctrines, philosophy, psychological and social science, and even such redoubtable areas as the physical science and mathematics" (Blumer, 1968:342). It is, in fact, hard to a priori exclude an area from the analysis of fashion.

Fashion is different from innovation, style, and trend. Fads refer to processes of diffusion of things or activities that normally include many actors, such as when the skateboard was introduced. Fads do not have a history of replacing each other. Fashion, furthermore is different from innovation. Both fashion and innovation replace something existing, such as an older fashion or an existing practice or technique, but innovations permanently alter the social practice or things, for example, the material people use to insulate houses. An innovation, hence, has lasting effects, and may be seen as a progress according to a scale of evaluation. Fashion is different from style, which refers to a multidimensional self-referential aesthetic system produced and extended over. The styles of punk or Goth are examples. A trend, finally, is a process with an identifiable direction over time, such as when people are dining out more frequently. A trend, for example, of how one should present food, thus, may encompass several fashions, of where one 'should' eat out in various cities.

Fashion was once a limited phenomenon, with very few in a society able to participate. In modern societies, however, economic well-being has made it possible for the vast majority in many countries around the globe to participate in the 'fashion race.' Wealth is not the only factor; however, people also enjoy far greater psychological mobility, and the new form of communication it generates makes fashion more important today. In Psychologie économique (1902), Tarde coined the term 'inter-psychologie.' Society is the sum of people's mental condition in constant interaction. Free time and consumption become increasingly significant vehicles for such communication. New needs are born out of this mental interaction.

Social science research has for almost 100 years treated fashion as a field of lesser importance. Researchers, not the least sociologists, have over the last 15 years paid more attention to fashion, especially to the production of fashion, and there is today also an emerging discipline called fashion studies. It is at the same time clear that the field needs more theoretical development.

\section{Fashion in Different Societies}

Fashion's universal nature does not preclude strong variations in its social significance from society to society. Thus, Tarde (1903) differentiated between customary and fashionable 
societies. In the former, people see custom as governing their lives; they are more passionate about their country than about their period because custom prizes the past above all. In periods where fashion predominates, people are instead prouder of their era than their country.

Variations between societies are thrown up by different conditions. In economically stagnant periods, conventional stratification variables such as class and income are more decisive in people's lifestyles. In economically expansive periods, increasing importance is laid on fashion instead. Modern society is often contrasted with earlier epochs, and it is argued that fashion's role has markedly increased, although many reasons are given for the change. An influential argument is that the differences in lifestyle of different groups have increased in number and scope, making it possible for people to exhibit their group's distinctive nature.

Simmel sees the 'need for distinction' and the 'need for union' as preconditions for fashion. Certain societies therefore lack the necessary motivation. Simmel (1904) mentions that in fourteenth-century Florence, male dress was devoid of fashion. The 'need for union,' the need to express how certain groups were distinct from others with the help of fashion, was absent, and everyone could dress according to personal preference. Another of Simmel's examples was Venice at the same time. Again, we find that fashion is absent from upper-class dress. Venetian aristocrats were ordered to dress in black so that the lower classes would not know how few they were. They did not want to differentiate themselves, and thus the 'need for distinction' that fashion requires was missing. Their 'uniform' can be interpreted as one dimension of what constitutes their status group, as Weber would call it.

Variations in fashion's importance have also been tied to women's standing in society. According to Veblen (1899), it was woman's role to be a vicarious consumer; her consumption symbolized the man's wealth, and thus she became the vehicle of fashion. In Simmel (1904), however, we find an early formulation of compensation theory. Fashion acts as a safety valve. Deny women self-expression in other areas, and the only thing left for them is fashion. In fourteenth- and fifteenth-century Germany, the chance of personal development had increased, which, however, was denied to women. Rarely have more 'hypertrophic' modes of female dress been seen than in this period.

Simmel (1904) further explains fashion differences between societies. Fashion has two fundamental, symbolic functions: an ability to mark difference and an ability to express community. In many nonindustrialized societies, the need for union is acute, while the need for distinction is weak. Simmel mentions certain African tribes who lacked both class differentiation and the concomitant need to signal differences. Where people in these societies want to note differences, it is often a matter of open hostility, which in turn is sterile ground for fashion. Given that fashion functions best where the distance between groups is otherwise only vaguely established, in instances where open hostility already exists, fashion as a sociological form becomes meaningless.

A similar argument can be found in König (1974), who identifies three different stages in society, each with a different type of fashion. The first significant historical change was the emergence of a fixed class hierarchy; at this stage, fashion is the preserve of exclusive, feudal nobility. In the second stage, rigid differences between upper and lower classes are weakened; lower classes adopt the fashion of the elite, ultimately forcing it to alter fashion constantly to retain its individuality. The third stage sees the development of egalitarian democracies and industrial technology. This modern form of society brings with it the spread of fashion through mass consumption.

\section{Fashion as a Process of Change}

Fashion is about change, but this change presumes that other things are ordered; if not, changes would not be perceived. The question of what drives fashion's continuous changes has kept researchers busy, and a series of different theories has been given in answer. In Simmel's analysis of fashion, we find a foretaste of many of the theories that were to follow.

\section{Social Differentiation}

Many have stressed fashion's origins in class. Though class has its origin in production, its cultural and symbolic meaning is expressed by means of consumption. The analysis by Veblen (1899) of patterns of fashion dispersal has become a classic. A fashion begins with the 'leisure class,' the group with most money. It is attractive to this class because fashion items cost a great deal more than regular items. By degrees, the fashion is adopted by the upwardly aspiring middle classes. Simmel (1904) also describes how fashion must constantly be supplied with new content if it is to give social expression both to similarities within groups and differences between them. To describe fashion's downward spread through society, the trickle-down model was adopted by Barber and Lobel (1953), who dismissed the argument that fashion is irrational as obscuring its connections with the economic system. Meanwhile, named for the imitation of the elite that brings in turn an alteration in elite habits, we have the chase and flight model.

Bell (1976) follows Veblen in seeing economic competition as a force behind changes in fashion. Dress for the middle and upper classes is an expression of wealth. This wealth can be expressed in the form of conspicuous consumption, conspicuous leisure, and conspicuous waste. To these, Bell adds his own category of conspicuous outrage to convey the fashion-setting classconscious choice of clothing that does not conform with prevailing notions of good taste.

The theory that fashion is the means of social distinction for the upper classes in a hierarchical society has had great influence. Mimicry of social superiors and an urge to be different from 'inferiors' are often noted as the reasons for fashion's changes, while an individual's choice of style is seen as a significant means of securing his or her position in society. Such choices often establish their distance from those below them in the social pecking order and express subtle distinctions of degree within one and the same class. Researchers who present other models often start from the theory of social differentiation, even if they distance themselves from its application to today's society. Some argue that the idea that fashion was the distinguishing mark of the elite was probably valid in the eighteenth and nineteenth centuries, but this is less 
so today. It has been argued that the traditional upper class has lost its fashion primacy to be replaced, for example, by today's powerless elite. This new elite, termed Divi by Alberoni (1967), uses the mass media to present new lifestyles and new consumption. Theories stressing that ideas through the means of trend scouts also move from the street to the designers and thus affecting or even determining fashion have been presented. Others have discussed how subgroups, for example, Goths (Hodkinson, 2002) have developed their own fashions. It is nonetheless fair to say that one cannot speak of one fashion only, but of fashions.

\section{Fashion's Inner Dynamic}

Simmel's analysis included a further suggestion of what drives fashion. Fashion is made up of internal, conflicting forces that necessarily lead to change; it is distinguished by differentiation and union, superficiality and profundity, freedom and dependence, individuality and imitation, destruction and construction, leadership and submission. Antagonistic forces are united in fashion in a way that ensures continual change. Nedelmann (1990) develops the idea of the inherently contradictory nature of fashion, describing its Eigendynamik. Fashion, by its nature, contains a stimulus for change derived from polar opposites. People like to imitate, thus spreading a certain fashion, but are equally drawn to differentiation. Imitation leads to the spread of fashion, while new ideas and differentiation lead to its contraction. Nedelmann invokes Simmel, writing that the greater the degree of concord within the upper classes, the more frantic the search for imitation from beneath, and the more constant the search for new fashions by the upper classes. On the other hand, the more the members of the lower classes use style to differentiate between themselves, the less the upper classes are inclined to come up with new fashions. Fashion in this society thus has less significance.

Davis (1992) has also noted the ambivalence of fashion, and identifies its source in sexuality. Davis writes of a continuous dialectic in clothing between the erotic and the modest. Sellerberg (1994) similarly stresses the significance of antagonism as a driving force of change. Fashion reduces and creates complexity. It is a continuous break with authority, but its break is authoritative: 'this is what matters, for now.' In this contradiction one finds the motor of change.

\section{System Theories}

Davis (1992) differentiates between two types of sociological model used to explain the dissemination of clothing styles. The first, the populist model, centers on the consumer's role and the laymen's innovations in dress. Researchers who use the populist model study general consumption, for example, how groups such as teenagers, surfers, gays, skateboarders, or feminists set their own stamp on fashion. The other model is a system model. Some system models are predicated on the existence of established social centers for innovation, for example, Paris or Milan, with their fashion shows, designers, editors, wholesalers, and stylists. The fashion system is here seen as a closed circle of producers, distributors, and consumers (Kawamura, 2004).
The trickle-down theory has been criticized by system theorists because it does not focus on the complex structures of organizations and marketing that channel and mediate the fashion process. Those who use a system model aim to analyze the influence of the different elements of the fashion system. One subject of controversy has been whether designers are creative interpreters or merely passive intermediaries in the commercially vital process of heeding consumers' wishes and reconciling them with the producers' requirements.

\section{Fashion as a Break with Convention}

The destruction of what exists and the construction of something new in the process are the elements that unite in fashion, according to Simmel. Researchers who today see fashion as breaking current rules usually identify groups other than the socioeconomic upper class as leading fashion. Campbell (1992) has criticized the class differentiation theorist's explanations and identifies different types of 'new': the new, the innovative, and the novel. The novel - new as different - is central to fashion as it breaks with what already exists. The necessary conditions for creating novelty exist in peripheral groups such as bohemians and artists. It is these groups who set fashion in motion, not an upper class. To argue that fashion is unconventional, however, is also to argue that fashion continuously reestablishes social conventions and social order. Blumer (1969) sees both similarities and differences between fashion and custom. In both cases, it is a question of social ordering. Custom, however, is static or changes only slowly, while fashion is a constant creator of social order. In Blumer's argument, every fashion emerges from an intensive process of 'collective selection.' The alternatives that are ultimately selected become fashion in different areas. Fashion conjures order out of the vast jumble of possible styles where no objective norm can determine 'right' or 'wrong.'

\section{Fashion as a Psychological and Social Expression}

Psychologically oriented theories of fashion frequently center on general human needs such as the wish to be appreciated. It is often pointed out that people's need to display and strengthen their ego is particularly strong. Fashion has great shock value in the hunt for self-expression; it provides a tangible 'look at me.'

In a discussion of fashion as an expression of personality, we can return to Simmel. Fashion makes it possible to express opposites. While conveying personality (paradoxically in the extreme imitation of the modern), it also offers the chance to avoid conveying individuality, and thus functions as the ego's 'iron mask.'

Fashion offers a means of psychological expression, but also a social expression of protest. People express in fashion the impulses and wishes that are not sanctioned by normal social conventions. There is thus a constant tension between the more established 'domain of culture' and the marginal 'domain of fashion.' In fashion, young people express their stance through wearing what König (1973) calls 'anti-fashion.'

The idea of fashion as a vehicle of social protest has been criticized, however. Protest styles are usually incorporated into fashion and exploited economically (Emberley, 1987). 
Others argue that fashion's break with convention is actually a pseudodeviation. Although certainly defying convention, each break loses its original edge as soon as it is expressed in fashion (Wilson, 1985).

Fashion has been interpreted as an expression of the search for a personal identity in an insecure world, and 'fads and fashions' as an expression of the worry that typifies our time. This has sometimes been interpreted as a negative phenomenon. Blumer (1969) thinks that the operation of fashion becomes natural in a changing world where people must continuously cut their ties with the past. Individuals are liberated from earlier models, and orient themselves toward the future. The importance of fashion is as clearly seen among those who follow or try to determine fashion, some of whom turn into 'fashion victims,' as among those who actively argue for an antifashion. Regardless of which attitude a person has, it is hard to stay 'outside' of fashion.

\section{The Production of Fashion}

Fashion is not only an effect of the increasing wealth, it is a social phenomenon that drives the economy. Since the mid-1990s sociologists have studied the production of fashion, and looked into the conditions and effects of how fashion is produced. This research has focused on the garment industry, but in contrast to much of the earlier sociological work, consumption and social distinction have not been in the foreground. But the focus has not only been on garment production, but on the institutions, actors, and logic of fashion production - how it comes to be that some garments, models, photographers, or styles come into fashion, and others not (Entwistle, 2009). The general point being made is that fashion is a collective, though not a concerted, product, and that various producers, including, designers, models, fashion photographers, magazines, buyers, and many other coproducers of fashion, are involved in this production. Several authors have contributed to this field. One study that represents this field of research is a sociological analysis of fashion with a focus on global garment markets (Aspers, 2010). The study shows how the final consumer market for fashion garments in Western Europe is intimately tied to the markets for production of these garments, located in countries where the cost of production is low. Others have studied fashion magazines (Moeran, 2006) and what they do to affect the current fashion and fashion models. The fashion industry is one of the largest in the world, and the economic side of fashion, however, is not only restricted to garments.

\section{Fashion's Cycles}

Some researchers have been less interested in fashion's social dynamic than in an in-depth descriptive study of its cycles. Richardson and Kroeber (1940) use empirical data to identify six different formal aspects in women's dress taking, for example, the changes in length and width of skirts over 300 years. A number of researchers have followed Kroeber's empirical tradition, in which specific changes in fashion are seen to occur within a continuous cycle of longer periods. For example, Robinson (1976) studied beard fashions between 1842 and 1972 as time series analyses. To understand the elapse between the reappearance of the same fashion, Robinson argues that certain ground rules apply for fashion's cyclical changes, one being that as long as a number of people still follow a certain fashion, it prevents younger people from adopting it.

Fashion in this perspective is not born, but is rediscovered. Cross-cyclical changes receive particular attention as demonstrating sharp reactions to extreme styles. For example, the streamlined form's soft curves are contrasted with the ensuing period's particularly angular design. Cycles are not only restricted to garments. Stanley Lieberson (2000) has shown that personal names have a strong cyclical pattern.

\section{Ambivalence Toward Fashion: The Vitally Unimportant}

Fashion is dubious, and especially economists, for example, Pesendorfer (1995) have often criticized fashion for being the primary example of irrationality - and thus something that should be abolished. Fashion's symbolic significance has been contrasted with its lack of practicality. This has led many today to express ambivalence toward fashion, and there is a tendency to legitimize it using functional arguments; the rational and practical is acceptable where the impractical is not. Function and symbolism can sometimes be reconciled in fashion, however. Aerodynamics has been described as a discovery of great significance for industrial design, and for a time all household appliances were streamlined. 'Streamlining' symbolized America's enlightened practice of throwing over old conventions to create a new and dynamic civilization. Those who chose, for example, a streamlined kettle, demonstrated that they also chose the rational, the future, and the practical.

\section{Fashion as Unpredictable}

Increasingly, fashion's analysts, as stated by Aspers and Godart (2013) have come to emphasize the inner dynamic in fashion. Individual theories are run together to reflect fashion's inherent contradictions: it is coercion and individual choice; it is social order and a break with social order; it is union and differentiation. The nature of fashion is seen as ever more complex.

There is a more simplistic perspective, however, common to those who base their interpretation of fashion on industrial products. Here one finds phrases such as 'the most thorough logic of planned aging,' and 'industry is based on extolling a perpetual neology.' Fashion, however, is to be found everywhere, not only in areas that are subject to commercial planning, while the aging of fashion is impossible to predict precisely, however much industry demands precise guidelines. The problems stem from fashion's most central characteristic: because it symbolizes 'now,' it can never be foreseen with any certainty. Fashion pinpoints what is right in the present, but the moment it can be predicted accurately, it is no longer a matter of fashion. The transient symbols of what is right for now can never be nailed down in advance. 
See also: Art and Culture, Economics of; Collective Action; Collective Behavior, Sociology of; Consumer Psychology; Consumption, Sociology of; Culture, Sociology of; Differentiation: Social; Fashion, Sociology of; Hegemony and Cultural Resistance; Simmel, Georg (1858-1918); Social Identity in Sociology; Values, Sociology of.

\section{Bibliography}

Alberoni, F., 1967. Consumi e società. Società editrice il Mulino, Bologna, Italy. Aspers, P., 2010. Orderly Fashion, A Sociology of Markets. Princeton University Press, Princeton, $\mathrm{NJ}$.

Aspers, P., Godart, F., 2013. Sociology of fashion: order and change. Annual Review of Sociology 39, 171-192.

Barber, B., Lobel, L.S., 1953. Fashion in women's clothes and the American socia system. In: Bendix, R., Lipset, S.M. (Eds.), Class, Status and Power. Free Press, Glencoe, IL, pp. 323-332.

Bell, Q., 1976. On Human Finery. Hogarth Press, London.

Blumer, H., 1968. Fashion. In: Sills, D. (Ed.), International Encyclopedia of the Socia Sciences, vol. 5. The Macmillan Company, London, pp. 341-345.

Blumer, H., 1969. Fashion: from class differentiation to collective selection. Sociological Quarterly 10, 275.

Campbell, C., 1992. The desire for the new. Its nature and social location as presented in theories of fashion and modern consumerism. In: Silverstone, R., Hirsch, E. (Eds.), Consuming Technologies: Media and Information in Domestic Spaces. Routledge, London, pp. 48-66.

Davis, F., 1992. Fashion, Culture and Identity. University of Chicago Press, Chicago, IL. Emberley, J., 1987. The fashion apparatus and the deconstruction of post-modern subjectivity. Canadian Journal of Political Social and Theory 11, 38.
Entwistle, J., 2009. The Aesthetic Economy of Fashion: Markets and Value in Clothing and Modelling. Berg, Oxford.

Hodkinson, P., 2002. Goth, Identity, Style and Subculture. Berg, Oxford.

Kawamura, Y., 2004. The Japanese Revolution in Paris Fashion. Berg, Oxford.

König, R., 1973. The Restless Image: A Sociology of Fashion. Allen \& Unwin, London.

König, R., 1974. A la Mode: On the Social Psychology of Fashion. Seabury Press, New York.

Lieberson, S., 2000. A Matter of Taste: How Names, Fashions, and Culture Change. Yale University Press, Yale.

Moeran, B., 2006. More than just a fashion magazine. Current Sociology 54 (5), 725-744.

Nedelmann, B., 1990. Georg Simmel as an analyst of autonomous processes: the merry-go-round of fashion. In: Kaern, M., Phillips, B.S., Cohen, R.S. (Eds.), Georg Simmel and Contemporary Sociology. Kluwer, Dordrecht, The Netherlands.

Pesendorfer, W., 1995. Design innovation and fashion cycles. The American Economic Review 85 (4), 771-792.

Richardson, J., Kroeber, A.L., 1940. Three Centuries of Women's Dress Fashions: A Quantitative Analysis. University of California, Berkeley, CA.

Robinson, D.E., 1976. Fashions in shaving and trimming of the beard: the men of the illustrated London news, 1842-1972. American Journal of Sociology 81, 1133-1141.

Sellerberg, A.-M., 1994. A Blend of Contradictions: Georg Simmel in Theory and Practice. Transaction Publishers, New Brunswick, NJ.

Simmel, G., 1904. Fashion. Fashion International Quarterly 10, 130-155.

Tarde, G., 1902. Psychologie Economique. F. Alcan, Paris.

Tarde, G., 1903. Laws of Imitation (Trans. from the 2nd French Edition, Parsons E.C.). In: Custom and Fashion. Holt, New York (Chapter vii).

Veblen, T.B., 1899. The Theory of the Leisure Class: An Economic Study in the Evolution of Institutions. MacMillan, New York.

Wilson, E., 1985. Adorned in Dreams. Virago, London. 